\title{
How family background shapes the relationship between human capital and fertility
}

\author{
Francis Kramarz $^{1,4} \cdot$ Olof Rosenqvist ${ }^{2,3} \cdot$ Oskar Nordström Skans ${ }^{2,3,4}$ (D)
}

Received: 13 July 2019 / Accepted: 13 February 2021 / Published online: 13 March 2021

(C) The Author(s) 2021

\begin{abstract}
Many previous studies have shown that skilled and educated women have fewer children. By comparing twins and close siblings in Swedish register data, we show that the negative association between human capital and fertility mostly reflects family background factors. For males, human capital measures are unrelated to fertility in the overall population, but this again masks the influence of family background factors as high-skilled males tend to have more children than their less-skilled twins or siblings. Hence, family background factors have a strong negative impact on the overall association between human capital measures and fertility for both women and men. Non-cognitive abilities deviate from these patterns - these abilities remain strongly complementary to fertility both within and across families. Our results can be reconciled with a stylized model where family-specific preferences for fertility are shared across generations and shape investments in skills and traits when children are young.
\end{abstract}

Keywords Fertility $\cdot$ Education $\cdot$ Grades $\cdot$ Cognitive ability $\cdot$ Non-cognitive ability $\cdot$ Twins

JEL codes: J13 $\cdot \mathrm{J} 24$

Responsible editor: Shuaizhang Feng

Oskar Nordström Skans

oskar.nordstrom_skans@nek.uu.se

Francis Kramarz

francis.kramarz@ensae.fr

Olof Rosenqvist

olof.rosenqvist@ifau.uu.se

1 CREST, Paris, France

2 IFAU, Uppsala, Sweden

3 UCLS, Uppsala, Sweden

4 Uppsala Universitet, Uppsala, Sweden 


\section{Introduction}

The relationship between fertility and human capital measures such as skills and education is a widely studied topic within the social sciences. Although the literature has converged on the conclusion that fertility rates decline as a country's population becomes more educated (see, e.g., Frejka and Calot 2001 and Fort et al. 2016), ${ }^{1}$ such conclusions are less clear at the individual level. If pursuing higher education makes it more costly to raise a family, then individuals may be forced to choose between accumulating more human capital and raising children, a fear that appears relevant for career-oriented women in many countries. On the other hand, human capital may be complementary to fertility if it increases attractiveness on the marriage market relative to competing peers. At the same time, a separate, but equally large, literature has documented that human capital indicators, family values, and other key determinants of social and economic outcomes are shared within families and transmitted across generations. These patterns naturally raise questions regarding the extent to which associations between education and fertility are artifacts of transmitted family traits, and how such a transmission process is best understood. Family-based skill endowments, but also wealth and preferences, may affect both the possibilities of pursuing higher education and fertility outcomes. In this paper, we present the most comprehensive evidence yet on the role of shared family background for shaping the associations between skills, education, and fertility outcomes. We also provide a stylized theoretical framework that can explain the empirical patterns we unravel.

We analyze the role of family background for fertility outcomes of both men and women using data from Swedish population-wide intergenerational registers. We link to those data a very broad set of human capital measures covering years of schooling, compulsory school grades, cognitive ability, and non-cognitive ability, all drawn from Swedish register data. Key to our analysis is that our intergenerational registers allow us to isolate pairs of twins or close siblings who share a joint family background. ${ }^{2}$

The bulk of the existing literature has found negative associations between fertility and education, at least for females. ${ }^{3}$ But this (raw) empirical association is likely to be confounded by predetermined factors, such as skill endowments, preferences, and wealth, that may affect both the pursuit of higher education and fertility outcomes. As we conjecture that an important set of confounders are shared within families, we aim to provide a detailed assessment of how family background affects the associations between education, skills, and fertility. The aim is to isolate the full impact of a shared family background without restricting the analysis to dimensions that are measurable in available data. ${ }^{4}$ Empirically, we therefore follow in the tracks of a set of recent studies that removed the confounding impact of family background by controlling for family

\footnotetext{
${ }^{1}$ The main reason is that education improves earnings capacity, making it more costly to bear and raise children. In addition, education leads to increased awareness of contraceptive technologies.

${ }^{2}$ Whenever we refer to "family background" in this paper, it should be interpreted as "all parts of family background that are shared across twins (or close siblings)". It does not include child-specific idiosyncratic components that may arise if parents have specific preferences for some of their children or if they invest in response to child-specific initial conditions.

${ }^{3}$ See Section 2 below for a detailed discussion of specific studies.

${ }^{4}$ The focus on isolating the full impact of parental background comes at the cost of not being able to separate between precise (mediating) characteristics of the parents.
} 
fixed effects when regressing fertility measures on education (see, e.g., Amin and Behrman 2014; Kohler et al. 2011; Nisén et al. 2013; Nisén et al. 2014; Nisén et al. 2018). The evidence from these studies is mixed; perhaps partly because of small sample sizes, but the overall pattern tends to suggest that the inclusion of family fixed effects reduces the negative association between education and fertility. Several papers have relied on compulsory schooling reforms to directly estimate the causal impact of education on female fertility (see, e.g., Cygan-Rehm and Maeder 2013; Fort et al. 2016; Grönqvist and Hall 2013; Monstad et al. 2008). However, the results are mixed, and the lack of statistical precision makes the approach less useful for our purposes as it makes it difficult to precisely isolate the role of family background factors.

A related set of studies have directed attention to the association between initial skill endowments (mainly intelligence) and fertility (see, e.g., Chen et al. 2013; Kanazawa 2014; Meisenberg 2010; Wang et al. 2016), thus focusing on the impact on fertility of endowments that are predetermined at the time when schooling and fertility choices are made. Generally, the above studies document a negative association between intelligence and fertility for women and a relationship close to zero for men. In a recent paper, Kolk and Barclay (2019) find a positive relationship between skills and fertility for men after controlling for family background factors. ${ }^{5}$

In this paper, we combine elements of these earlier approaches, but with a sharper focus on the role of family background factors instead of the causal impact as such. This focus relates our study to the enormous literature on how shared family factors that affect individual outcomes are transmitted across generations. A large number of empirical studies document that families share, within and across generations, fundamental traits and outcomes such as cognitive and non-cognitive abilities (e.g., Grönqvist et al. 2017 and references therein), education (see Fleury and Gilles 2018 for a meta analysis and Havari and Savegnago 2020 for a recent study), family values (e.g., Yi et al. 2004; Copen and Silverstein 2008), and criminal behavior (see Besemer et al. 2017 for a meta analysis and Dobbie et al. 2018 for a recent study) just to name a few. But to the best of our knowledge, this literature, which also inspired a set of theoretical models to explain the underlying processes (see, e.g., Caucutt and Lochner 2020 for a recent example), has not scrutinized the extent to which shared family traits shape the joint distribution of human capital, education, and fertility.

We analyze how family background affects the relationships between skills and fertility and between educational attainment and fertility using twin and sibling fixedeffects models. An advantage relative to most previous fertility studies is that we are able to use nationwide register data on several different measures of human capital. These measures cover standard outcomes related to completed education and fertility ${ }^{6}$ as well as skill endowments in the form of grades and cognitive and non-cognitive abilities (for men only) ${ }^{7}$ measured before family formation and entry into further education. One unique feature of the data is the possibility of precisely estimating the

\footnotetext{
${ }_{5}^{5}$ Our focus is different from Kolk and Barclay (2019) in the sense that we are more explicitly interested in explaining the nature of the family background bias (see, in particular, our ending section). We therefore use a much broader set of skill-measures for both men and women.

${ }^{6}$ Our fertility measures are: Age at first birth (AFB), a dummy for having children at all at age 45 and the number of children at age 45 .

${ }^{7}$ We show that the cross-family patterns are similar for men and women in those dimensions where we do not have individual skill data for women.
} 
relation between fertility and cognitive and non-cognitive ability within male twinpairs. This is a novel contribution in its own right; in particular as non-cognitive abilities otherwise mostly tend to be available in small-scale survey data sets that do not allow for the inclusion of family fixed effects. We show that these non-cognitive abilities are less related to educational performance than cognitive abilities (that instead are highly correlated with school grades) but instead matter more for family formation outcomes. Overall, we are able to give a very comprehensive picture of the role played by family background factors in forming the relations between skills, education, and fertility for men and women.

Our results highlight that family background is a key determinant of the raw empirical associations between human capital measures and fertility. For women, we find significant negative raw associations between years of schooling, compulsory school grades, and fertility, as in most previous studies. However, after accounting for twin (or sibling) fixed effects, the associations are close to zero. For men, the raw associations between human capital (years of schooling, compulsory school grades, and cognitive skills) and fertility are close to zero, but after accounting for twin (or sibling) fixed effects, estimates become positive.

Overall, we thus conclude that the raw associations overemphasize (relative to the within-family associations) the degree to which human capital accumulation crowds out childbearing for women. The raw associations similarly underestimate the degree of complementarity between human capital and fertility for men. These patterns imply that there must exist some important family background factor (shared between twins and siblings) that is positively related to grades, cognitive abilities, and acquired education but negatively related to our fertility measures (consequently pushing the raw associations in a negative direction) for both men and women. With respect to non-cognitive ability, which has not been studied in the previous literature and which we show to be very strongly positively related to fertility, we instead find the opposite pattern; the inclusion of twin fixed effects pushes the association with fertility in a more negative direction.

We end the paper by showing that all of these patterns can be reconciled in a stylized theoretical model where shared preferences within a family are allowed to affect both the types of skills children accumulate and the choices these children make later in life. We postulate, in line with our empirical patterns, that cognitive skills are relatively more important for schooling whereas non-cognitive skills are more important for marriage and fertility. Families with relatively strong preferences for education then have incentives to focus their skill investments in the cognitive domain, whereas families with a relatively strong preferences for fertility have an incentive to focus more on raising children with non-cognitive skills. If the underlying preferences also are transmitted across generations, this justifies why fertility is particularly low in families where children have high education/cognitive skills. As a consequence of the shared intergenerational traits, these associations will always be more negative across families than within families. A first-order testable prediction is that parents with high education (fertility) conditional on the own skill-set should raise children with more cognitive (non-cognitive) skills. We show that this prediction is borne out in the data.

The paper is structured as follows: Section 2 presents an overview of the existing literature. Section 3 presents our Swedish register data. Section 4 presents the main 
empirical results. Section 5 presents the theoretical model and tests thereof. Section 6 concludes.

\section{Previous literature}

The overall literature on the determinants of fertility outcomes is clearly much too vast to be summarized here. Instead, we give a broad overview of the most closely related studies, i.e., papers presenting findings concerning the associations between years of schooling, cognitive skills and non-cognitive skills on the one side, and individual fertility measures on the other side. ${ }^{8}$

For women, years of schooling is generally negatively associated with completed fertility (Amin and Behrman 2014; Kravdal and Rindfuss 2008; Meisenberg 2008; Nisén et al. 2013). However, at least in the Nordic countries, there have been substantial changes over time. Andersson et al. (2009) and Jalovaara et al. (2019) report that the educational gradient in completed fertility has decreased over time. The crosssectional association between years of education and Age of First Birth (AFB) for women is consistently positive (Amin and Behrman 2014; Kravdal and Rindfuss 2008; Martin 2000; Rodgers et al. 2008; Tropf and Mandemakers 2017).

The results for men are more mixed. In developed countries the association between years of schooling and completed fertility is suggested to be zero or slightly positive (Kravdal and Rindfuss 2008; Meisenberg 2008; Nisén et al. 2013). For the Nordic countries, Jalovaara et al. (2019) report a persistent positive educational gradient in completed fertility. In developing countries, however, the association is firmly negative (Meisenberg 2008). But, it appears quite clear that higher education is associated with higher AFB for men (Kravdal and Rindfuss 2008; Nisén et al. 2013).

Recently, a set of papers has investigated within-twin associations between years of schooling and fertility, in an attempt to move closer to estimating a causal effect of educational attainment on fertility. ${ }^{9}$ Kohler et al. (2011) and Amin and Behrman (2014) investigate within-twin associations between years of schooling and fertility using data on identical female twins in the USA. Both studies find that more education is associated with lower completed fertility in terms of number of children. Amin and Behrman (2014) further suggest that education delays childbearing. However, they find no association between education and childlessness. Nisén et al. (2013) study male and female twin pairs in Finland and find no effect of education for any of the genders on completed fertility in terms of having children at all. ${ }^{10}$ Nisén et al. (2013) further shows that the within-twin association between years of schooling and AFB for men is close to zero while it is slightly positive for women. Rodgers et al. (2008) and Tropf and

\footnotetext{
${ }^{8}$ A condensed overview can be found in Table A1 in Kramarz et al. (2019).

${ }^{9}$ It is of course debatable whether within-twin pair estimates of the effect of education on fertility can be given a causal interpretation. But at the very least, family fixed-effects models remove the confounding influence of environmental factors that simultaneously determine fertility and education. See Kohler et al. (2011) for a detailed description of the benefits of twin data in social science.

${ }^{10}$ There are also papers that have performed similar analyses using siblings instead of twins. Nisén et al. (2014) show that the within-sibling association between education and completed fertility for Finnish women is negative. The corresponding association for Finnish men is positive (Nisén et al. 2018). In both cases, however, the inclusion of sibling fixed effects pushes the estimates in a somewhat positive direction relative to the unadjusted estimates.
} 
Mandemakers (2017) have also investigated within-twin associations between years of schooling and AFB for women using data on Danish and British twins. Rodgers et al. (2008) suggest that the effect of education on AFB is zero but Tropf and Mandemakers (2017) report significant (albeit small) positive effects.

There are also several papers that have used compulsory schooling reforms to study the causal effect of years of education on fertility outcomes. McCrary and Royer (2011) suggest that the causal effect of education on AFB for women is zero. Monstad et al. (2008), Grönqvist and Hall (2013), Black et al. (2008), Cygan-Rehm and Maeder (2013), and Silles (2011), on the other hand, report positive effects. For men, Grönqvist and Hall (2013) find zero effects of education on AFB and on fertility at age 32. The evidence on the causal effect of years of schooling on completed fertility for women is quite mixed. Fort et al. (2016) find negative effects for England but positive effects for continental Europe. Monstad et al. (2008) find zero effects. Grönqvist and Hall (2013) find zero effects (but measured at age 32). Cygan-Rehm and Maeder (2013) find negative effects.

Previous research on the raw association between cognitive ability/intelligence and fertility has produced two robust findings for women. First, intelligence is negatively associated with completed fertility (Chen et al. 2013; Kanazawa 2014; Meisenberg 2010; Wang et al. 2016). Second, intelligence is positively correlated with AFB (Rodgers et al. 2008). For men, the picture is less clear. Several recent papers report small negative associations between intelligence and completed fertility (Chen et al. 2013; Meisenberg 2010; Wang et al. 2016). Kanazawa (2014), however, does not find any relation between intelligence and childlessness, and Woodley and Meisenberg (2013) even find a positive association. Kolk and Barclay (2019), using data from Sweden, report that intelligence is positively associated with both completed fertility and AFB for men.

Research on the within-family association between intelligence and fertility outcomes is scarce. We are only aware of the papers by Rodgers et al. (2008) and Kolk and Barclay (2019). Rodgers et al. (2008) investigate the within-twin association between intelligence and AFB for women. They find a zero effect. Kolk and Barclay (2019) find that the unadjusted positive relationship between intelligence and completed fertility for Swedish men becomes even stronger when estimated within siblingpairs.

In our paper, we estimate associations between years of education, compulsory school grades, cognitive and non-cognitive abilities, and the three most commonly used fertility outcomes in the literature reviewed above, i.e., an indicator for positive completed fertility (having children at all at age 45), a continuous measure of completed fertility (number of children at age 45), and AFB. ${ }^{11}$ We do this separately for men and women. We focus on documenting how raw (within-cohort) associations differ from within twin-pairs (and close sibling pairs) estimates for all of these measures. ${ }^{12}$ This means that we, in contrast to earlier studies, can (i) give a comprehensive picture of the relations between grades, years of schooling, non-cognitive and cognitive skills

\footnotetext{
${ }^{11}$ To keep the presentation concise, and in concordance with the reviewed studies, we abstain from analyzing alternative measures such as parity progression ratios or parity at different ages.

12 Except within twin-pair associations for female ability scores which we cannot estimate for data availability reasons.
} 
on the one side and standard fertility measures on the other side and (ii) to isolate how family background affects all of these associations. We then collect the estimates and derive an intuitive stylized model that can account for the full set of patterns found in our data.

As discussed in the vast literature on twin fixed effects, not all confounders need to be related to family background. This implies that within-twin pair estimates may reflect differences in individual-specific factors that affect both human capital endowments and fertility. ${ }^{13}$ This should be kept in mind when interpreting our results. In terms of our key focus, this implies that all of our references to "parental background" should be interpreted as "those components of family background that are shared across twins (or siblings)".

\section{Data}

Our main data source is a multigenerational register covering all individuals in Sweden born in the period 1932-2017. This dataset contains year and month of birth, gender, and a personal identifier that can be linked to other registers. It also contains personal identifiers for the father and the mother. We approximate completed fertility by fertility outcomes at age 45. Consequently, we do not include individuals who are born after 1972. The included cohorts vary depending on the independent variables used; our largest (smallest) sample contains cohorts born between 1935 and 1972 (1969-1972). Through the multigenerational register, we can measure the reproductive results of these cohorts up until age 45 . We summarize their fertility through three different measures: AFB, a dummy for having children at age 45 and a count of the total number of children at age 45 .

This multigenerational register is also used to identify twins. Individuals that are born in the same month in the same year and that have the same mother and father are considered twins. We only study same-sex twins. We do not observe if the twins are monozygotic or dizygotic, but it is a well-known fact that about half of same-sex twin pairs are dizygotic (Haworth et al. 2008).

We measure skills and schooling using three different data sources. First, we have access to the final average grade from compulsory school for all individuals that graduated from 1985 onward. ${ }^{14}$ Students typically graduate from compulsory school in the year when they turn 16. Consequently, we can only study individuals born in 1969-1972 when using this skill measure. Second, we can observe cognitive and noncognitive ability test results for men from the military draft. The cognitive score, which is measured through a written test, is known to be a good measure of general intelligence (Carlstedt 2000). ${ }^{15}$ Non-cognitive ability is evaluated in the following way (Mood et al. 2012): During the draft, the draftees have a 20-min interview with a trained psychologist. The psychologist asks questions about how they behave and

\footnotetext{
${ }^{13}$ Thus, our measures of family background do not include idiosyncratic parental investments that may arise if, e.g., parents provide different types of stimulus to siblings with different pre-conditions as documented by Rosenzweig and Zhang (2009).

${ }^{14}$ We primarily think of compulsory school grades as capturing cognitive ability. In Table 3, we show results supporting this notion. We standardize the grades by graduation year.

${ }^{15}$ See Carlsson et al. (2015) for a detailed description of the tests of cognitive ability.
} 
perform in different situations and on the basis of the answers, the draftee is graded along four different dimensions: (1) social maturity (e.g., extroversion and independence), (2) psychological energy (e.g., focus and perseverance), (3) intensity (e.g., activation without external pressure), and (4) emotional stability (e.g., tolerance to stress). Unfortunately, the exact interview protocol is not released by the military. Fredriksson et al. (2018) show that each of the detailed scores is positively related to wages later in life, but also that different scores have different associations to the chosen occupation later in life which provide some additional insights into the nature of what they measure. For example, nurses have very high levels of "social maturity", miners have low overall ability levels, but comparatively much of "intensity", placement officers have very high levels of "psychological energy," and fire-fighters have very high levels of tolerance to stress. From the military's perspective, the aim of the non-cognitive score is to capture abilities that are believed to be productive in military situations but that are non-cognitive in nature. ${ }^{16}$ The subscores are summarized in an overall non-cognitive score reported using a normally distributed Stanine scale. The cognitive test results are summarized in a similar way, and we rely on these composite scores for the purpose of this paper after standardizing them to mean zero and standard deviation one by enlistment year (as in, e.g., Grönqvist et al. 2017) to handle some changes in measurement protocols during the sample period.

The draft typically occurs at age 18 which restricts our sample to individuals born in 1950-1972 (draft information is available from 1969). During this period, military service was compulsory for men and hence almost all men participated in the draft. Only a very tiny fraction of the women participated in the draft and thus this analysis is (primarily) confined to men. As shown by Grönqvist et al. (2017), it is possible to impute cognitive and non-cognitive abilities at the family level also for women by using the test results of their brothers. Using their method, we can therefore estimate raw associations across (but not within) families between skills and fertility also for women.

At the time of taking the draft tests, almost all subjects are still in school. Instead, almost all variation in years of schooling is beyond this point. The timing thus ensures that variation in years of schooling cannot have caused (much of) the variation in skills within our data, despite of the fact that participation in schooling is likely to add to the accumulation of cognitive and non-cognitive ability (see, e.g., Carlsson et al. 2015; Fredriksson et al. 2013).

Third, we can link our main dataset to a register called LOUISE (Longitudinal database about education, income, and employment). This register covers all individuals in Sweden aged 16-65 in a given year and contains data on the highest level of

\footnotetext{
$\overline{16}$ The measure of non-cognitive ability used in this paper is well established in the literature and has previously been shown to have a strong positive correlation with labor market outcomes even conditional on the cognitive score (see, e.g., Lindqvist and Vestman 2011; Fredriksson et al. 2013; Nybom 2017; Hensvik and Skans 2016; Grönqvist et al. 2017; Fredriksson et al. 2018). Grönqvist et al. (2017) report that the measure has a reliability of 0.5 , whereas Lindqvist and Vestman (2011) report a reliability of 0.7 . Lilieblad and Ståhlberg (1977) let different psychologists listen to tape recordings of the same enlistment interviews and then graded the draftees and the correlation between the non-cognitive scores assigned by the different psychologists was 0.85 . The correlation between our administrative-based measure of non-cognitive ability and other measures of non-cognitive ability used in the literature based on survey answers to questions related to, e.g., self-efficacy, self-esteem, conscientiousness and extraversion (see, e.g., Heckman et al. 2006; Nandi and Nicoletti 2014; Heineck and Anger 2010) is not known.
} 
education. We use LOUISE data from 2000 to 2013. Individuals born before 1935 do not appear in these data and thus the included individuals in this analysis are born between 1935 and 1972. We require that the individuals are at least 35 years of age when we measure their educational attainment. The highest education level variable is transformed into a continuous years of schooling variable. ${ }^{17}$ Table 1 gives an overview of the data we use.

Table 2 shows descriptive statistics for our main samples. The average number of children at age 45 lies between 1.6 and 2.0 depending on the sample; the probability of having a child at all at age 45 is between 0.75 and 0.87 , and the average AFB is between 25 and 30 . The differences are explained by known factors; women have higher fertility rates than men and later cohorts have children at older ages and are more likely to be childless (Andersson et al. 2009; Jalovaara et al. 2019). The overall impression is that twins are relatively similar to the average person in our key dimensions. Most notably, twins have only marginally fewer children on average. We also show that twins resemble each other in terms of skills and education, but that a non-trivial variation remains within twin pairs. The between twin-pair standard deviation in years of schooling for men is 2.4 whereas the corresponding within twin pair number is 1.2 , for women the numbers are 2.3 and 1.1 . Turning to grades, we find a between twin standard deviation of 0.9 vs 0.3 within for both men and women. For both cognitive and non-cognitive abilities, the numbers are in the order of 0.9 between and 0.4 within twin pairs.

As a final descriptive analysis, Table 3 shows the relationships between skills, grades, and years of schooling for men. Two things should be noted from Table 3. First, cognitive skills are contributing more to the final average grade from compulsory school than non-cognitive skills (consistent with results in Grönqvist et al. 2017 and Almlund et al. 2011). This is true for the general population of men (column 1) as well as within male twin pairs (column 2). It also holds for women across families when we use imputed (family) skills (see Table C1 in Kramarz et al. 2019). Therefore, we primarily view compulsory school grades as capturing cognitive ability. Second, cognitive ability is a stronger predictor of years of schooling than non-cognitive ability. Again, this is true both for men in general (column 3) and within male twin pairs (column 4). Results for women follow the same pattern (see Table C1 in Kramarz et al. 2019).

\section{Empirical analysis}

We analyze our data using two straightforward regression models. Equation (1) is used to capture the raw association between fertility and skills/schooling:

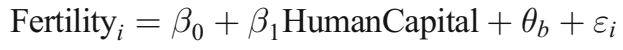

where fertility is measured in terms of AFB, a dummy for having children at age 45 and number of children at age 45 . We include birth year fixed effects $\left(\theta_{b}\right)$ to ensure that the

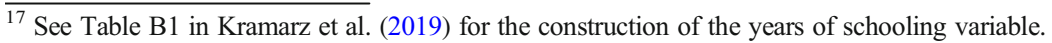


Table 1 Measures of skills and schooling for different cohorts

\begin{tabular}{lll}
\hline Measure of skills/schooling & Cohorts & Gender \\
\hline Years of schooling & $1935-1972$ & Men and women \\
Grades, compulsory school & $1969-1972$ & Men and women \\
Military draft scores & $1950-1972$ & Men \\
\hline
\end{tabular}

In order to observe fertility outcomes at age 45, we cannot study individuals born after 1972 . For women with brothers who have participated in the military draft we can impute cognitive and non-cognitive skills (see Grönqvist et al. 2017)

associations are estimated within birth cohorts. This model is estimated using the general population, and the estimate of $\beta_{1}$ therefore relies mainly on across-family variation. To remove the impact of family background that may jointly affect fertility and skills/schooling, we estimate Eq. (2) on the twin pairs (indexed by $j$ ) in our sample:

$$
\text { Fertility }_{\mathrm{ij}}=\beta_{0}^{W}+\beta_{1}^{W} \text { HumanCapital }+\delta_{j}+\varepsilon_{\mathrm{ij}}^{W}
$$

where $\delta_{j}$ represents a twin-pair fixed effect. The inclusion of this twin-pair fixed effect ensures that $\beta_{1}$ is estimated using within-family $(w)$ variation in fertility and skills/ schooling.

\subsection{Fertility and years of schooling}

We start by documenting the associations between years of schooling and fertility in Table 4. Results for females are presented in Panel A and for males in Panel B. The first column shows the (within birth cohort) raw associations between schooling and the number of children at age 45. Consistent with previous evidence, we find a significantly negative association for females; each additional year of schooling is associated with 0.04 fewer children. For males, we find a small (0.006), but statistically significant, positive association. This is consistent with the result in Jalovaara et al. (2019) who also use Nordic data. When introducing twin fixed effects in the second column, three quarters of the negative association for females disappears whereas the estimate for males becomes substantially more positive $(0.033)$.

Columns (3) and (4) present corresponding results for models where the outcome instead is a dummy for having at least one child by age 45 . The raw association for females suggests that 1 year of additional schooling is associated with 0.5 percentage points lower probability of having a child, whereas the estimate for males reveals a significantly positive association of approximately the same size. As in the case of the number of children, the introduction of twin fixed effects moves the estimates in a positive direction for both men and women.

The last two columns repeat the exercise for age at first birth (AFB). The sample now necessarily excludes those who never become parents and it is therefore somewhat smaller. We find that an additional year of schooling delays the first child birth by 0.66 years for females and by 0.45 years for males according to the raw association (column 5). Again, conditioning on twin fixed effects (column 6) moves the estimates in a 
Table 2 Descriptive statistics for our main samples (mean)
(1)
(2)

(3)

(4)

Panel A. Years of schooling sample (birth cohorts 1935-1972)

\begin{tabular}{lllll} 
& Men & \multicolumn{3}{l}{ Women } \\
& All & Twins & All & Twins \\
Year of birth & 1954.55 & 1954.87 & 1954.41 & 1954.46 \\
Years of schooling & 11.52 & 11.45 & 11.70 & 11.56 \\
Number of children at 45 & 1.83 & 1.74 & 2.01 & 1.92 \\
I [children at 45 > 0] & 0.80 & 0.77 & 0.87 & 0.85 \\
Age at first birth & 28.45 & 28.44 & 25.47 & 25.70 \\
Between-pair (std. dev.) & N/A & 2.43 (schooling) & N/A & 2.31 (schooling) \\
Within-pair (std. dev.) & N/A & 1.18 (schooling) & N/A & 1.12 (schooling) \\
Observations & $2,233,137$ & 19,758 & $2,180,083$ & 20,244
\end{tabular}

Panel B. Compulsory school grade sample (birth cohorts 1969-1972)

\begin{tabular}{lllll} 
& Men & \multicolumn{3}{l}{ Women } \\
& All & Twins & All & Twins \\
Year of birth & 1970.53 & 1970.61 & 1970.53 & 1970.60 \\
Grade (std) & -0.19 & -0.14 & 0.19 & 0.20 \\
Number of children at 45 & 1.65 & 1.64 & 1.88 & 1.78 \\
I[children at 45 > 0] & 0.77 & 0.76 & 0.85 & 0.82 \\
Age at first birth & 30.55 & 30.35 & 28.03 & 28.42 \\
Between-pair (std. dev.) & N/A & 0.95 (grade) & N/A & 0.88 (grade) \\
Within-pair (std. dev.) & N/A & 0.31 (grade) & N/A & 0.27 (grade) \\
Observations & 207,679 & 2070 & 201,634 & 2110 \\
Panel C. Military draft score sample (birth cohorts $1950-1972)$ & & \\
& Men & & Women (imputed within family) \\
& All & Twins & All & Twins \\
Year of birth & 1961.75 & 1961.59 & 1962.30 & N/A \\
Cognitive ability (std) & 0.00 & -0.16 & -0.02 & N/A \\
Non-cognitive ability (std) & -0.00 & 0.01 & -0.01 & N/A \\
Number of children at 45 & 1.73 & 1.69 & 1.97 & N/A \\
I [children at 45 > 0] & 0.77 & 0.75 & 0.85 & N/A \\
Age at first birth & 29.36 & 29.44 & 26.59 & N/A \\
Correlation (cog, non-cog) & 0.39 & 0.42 & 0.40 & N/A \\
Between-pair (std. dev.) & N/A & 0.92 cog, 0.87 non & N/A & N/A \\
Within-pair (std. dev.) & N/A & 0.41 cog, 0.46 non & N/A & N/A \\
Observations & $1,076,204$ & 10,784 & 225,226 & N/A \\
\hline
\end{tabular}

The grades are standardized with mean 0 and standard deviation 1 for each examination year. The skill measures are standardized with mean 0 and standard deviation 1 for each draft year. The between-pair (withinpair) standard deviation in number of children at age 45 for women is 0.95 (0.71) (sample is column 4 of panel A). The between-pair (within-pair) standard deviation in number of children at age 45 for men is $0.99(0.79)$ (sample is column 2 of panel A) 
Table 3 Relationships between skills, grades, and years of schooling for men

\begin{tabular}{lllll}
\hline & $\begin{array}{l}\text { Grade (std) } \\
(1)\end{array}$ & $\begin{array}{l}\text { Grade }(\mathrm{std}) \\
(2)\end{array}$ & $\begin{array}{l}\text { Education (years) } \\
(3)\end{array}$ & $\begin{array}{l}\text { Education (years) } \\
(4)\end{array}$ \\
\hline Cognitive skill & $0.6156^{* * * *}$ & $0.3346^{* * * *}$ & $1.0727^{* * *}$ & $0.5787^{* * *}$ \\
$($ std) & $(0.0018)$ & $(0.0286)$ & $(0.0023)$ & $(0.0381)$ \\
Non-cognitive skill & $0.2276^{* * *}$ & $0.0938^{* *}$ & $0.3167^{* * *}$ & $0.1253^{* * *}$ \\
(std) & $(0.0019)$ & $(0.0269)$ & $(0.0022)$ & $(0.0347)$ \\
Observations & 187,613 & 1780 & $1,027,581$ & 9984 \\
Mean of dep & -0.1515 & -0.1152 & 11.9671 & 11.9906 \\
Twin FE & No & Yes & No & Yes \\
\hline
\end{tabular}

The grades are standardized with mean 0 and standard deviation 1 for each examination year. The skill measures are standardized with mean 0 and standard deviation 1 for each draft year. In columns (1) and (3), we include year of birth dummies. We implicitly control for year of birth also in columns (2) and (4) since twins obviously have the same year of birth. In parentheses, we present standard errors clustered on the family level.

$\dagger p<.10 ; * p<.05 ; * * p<.01 ; * * * p<.001$

direction that is consistent with a less negative association between fertility and education (interpreting earlier births as a positive indicator of fertility). Within twin pairs, one additional year of schooling is only associated with a quarter of a year's delay for females and one sixth of a year for males. The results in columns 5-6 (panel A) are

Table 4 Fertility explained by years of schooling

No. of children No. of children Children $>0$ Children $>0$ AFB AFB
(1)
(2)
(3)
(4)
(5)
(6)

$\begin{array}{lllllll}\text { Panel A. Women } & & & & & \\ \text { Years of schooling } & -0.0412 * * * & -0.0114^{\dagger} & -0.0049 * * * & -0.0004 & 0.6629 * * * & 0.2637 * * * \\ & (0.0003) & (0.0066) & (0.0001) & (0.0021) & (0.0014) & (0.0285) \\ \text { Observations } & 2,180,083 & 20,244 & 2,180,083 & 20,244 & 1,898,864 & 15,228 \\ \text { Mean of dep } & 2.0061 & 1.9239 & 0.8706 & 0.8487 & 25.4741 & 25.6951 \\ \text { Twin FE } & \text { No } & \text { Yes } & \text { No } & \text { Yes } & \text { No } & \text { Yes } \\ \text { Equation } & (1) & (2) & (1) & (2) & (1) & (2) \\ \text { Panel B. Men } & & & & & & \\ \text { Years of schooling } & 0.0055^{* * *} & 0.0331 * * * & 0.0061 * * * & 0.0147 * * * & 0.4524 * * * & 0.1658^{* * *} \\ & (0.0003) & (0.0069) & (0.0001) & (0.0023) & (0.0015) & (0.0354) \\ \text { Observations } & 2,233,137 & 19,758 & 2,233,137 & 19,758 & 1,801,464 & 12,724 \\ \text { Mean of dep } & 1.8312 & 1.7444 & 0.7994 & 0.7697 & 28.4467 & 28.4442 \\ \text { Twin FE } & \text { No } & \text { Yes } & \text { No } & \text { Yes } & \text { No } & \text { Yes } \\ \text { Equation } & (1) & (2) & (1) & (2) & (1) & (2)\end{array}$

$A F B$, age at first birth. The outcomes in columns (1-4) are measured at age 45. In columns (1), (3), and (5), we include year of birth dummies. We implicitly control for year of birth also in columns (2), (4), and (6) since twins obviously have the same year of birth. In parentheses, we present standard errors clustered on the family level.

${ }^{\dagger} p<.10 ; * p<.05 ; * * p<.01 ; * * * p<.001$ 
very similar to what Tropf and Mandemakers (2017) found in their study on female twins in the UK.

\subsection{Fertility and grades}

In Table 5, we turn to an analysis of grades. Based on the results in Table 3, we argue that grades can be viewed as primarily capturing cognitive ability. The raw association between grades and the number of children for females (panel A, column 1) is negative and statistically significant at -0.060 for each standard deviation. The association for males (panel B, column 1) is smaller, but positive and significant. When adding twin fixed effects (column 2), the results become less precise because of the relatively limited sample, but in both cases, the estimates become more positive but insignificant. The results for the probability of having children follow the same pattern. The final two columns (5 and 6) repeat the exercise for AFB. Recall that we expect the opposite pattern with this outcome. Here, we find that both males and females have children later if compulsory school grades were higher, although more so for females. Adding twin fixed effects reduces the delaying effect of good grades for both men and women.

Overall, we conclude that the point estimates for grades have a similar relationship to fertility as years of schooling. Although the statistical precision for some of the estimates is quite poor due to small samples, we are reassured by the fact that widening

Table 5 Fertility explained by compulsory school grades

\begin{tabular}{|c|c|c|c|c|c|c|}
\hline & $\begin{array}{l}\text { No. of children } \\
\text { (1) }\end{array}$ & $\begin{array}{l}\text { No. of children } \\
\text { (2) }\end{array}$ & $\begin{array}{l}\text { Children }>0 \\
\text { (3) }\end{array}$ & $\begin{array}{l}\text { Children }>0 \\
\text { (4) }\end{array}$ & $\begin{array}{l}\text { AFB } \\
(5)\end{array}$ & $\begin{array}{l}\text { AFB } \\
(6)\end{array}$ \\
\hline \multicolumn{7}{|c|}{ Panel A. Women } \\
\hline Grade (std) & $\begin{array}{l}-0.0579 * * * \\
(0.0028)\end{array}$ & $\begin{array}{l}0.0031 \\
(0.0803)\end{array}$ & $\begin{array}{l}-0.0058^{* * * *} \\
(0.0008)\end{array}$ & $\begin{array}{l}0.0059 \\
(0.0315)\end{array}$ & $\begin{array}{l}2.0571 * * * \\
(0.0125)\end{array}$ & $\begin{array}{l}1.1518^{*} \\
(0.4495)\end{array}$ \\
\hline Observations & 201,634 & 2110 & 201,634 & 2110 & 171,479 & 1486 \\
\hline Mean of dep & 1.8760 & 1.7777 & 0.8500 & 0.8180 & 28.0331 & 28.4159 \\
\hline Twin FE & No & Yes & No & Yes & No & Yes \\
\hline Equation & (1) & (2) & (1) & (2) & (1) & (2) \\
\hline \multicolumn{7}{|l|}{ Panel B. Men } \\
\hline Grade (std) & $\begin{array}{l}0.0356 * * * \\
(0.0027)\end{array}$ & $\begin{array}{l}0.1493^{\dagger} \\
(0.0838)\end{array}$ & $\begin{array}{l}0.0132 * * * \\
(0.0009)\end{array}$ & $\begin{array}{l}0.0775 * * \\
(0.0284)\end{array}$ & $\begin{array}{l}1.3831 * * * \\
(0.0134)\end{array}$ & $\begin{array}{l}-0.1869 \\
(0.4722)\end{array}$ \\
\hline Observations & 207,679 & 2070 & 207,679 & 2070 & 160,250 & 1322 \\
\hline Mean of dep & 1.6507 & 1.6440 & 0.7684 & 0.7614 & 30.5544 & 30.3472 \\
\hline Twin FE & No & Yes & No & Yes & No & Yes \\
\hline Equation & (1) & (2) & (1) & (2) & (1) & (2) \\
\hline
\end{tabular}

$A F B$, age at first birth. The outcomes in columns (1-4) are measured at age 45 . The grades are standardized (std) with mean 0 and standard deviation 1 for each examination year. In columns (1), (3), and (5), we include year of birth dummies. We implicitly control for year of birth also in columns (2), (4), and (6) since twins obviously have the same year of birth. In parentheses, we present standard errors clustered on the family level ${ }^{\dagger} p<.10 ; * p<.05 ; * * p<.01 ; * * * p<.001$ 
the sample to include all close siblings gives a similar picture, but with better statistical precision (see the Appendix for the sibling estimates).

\subsection{Fertility and draft skill measures}

Next, we turn to an analysis of cognitive and non-cognitive skills. These measures are sourced from military draft registers and are only available for men. Following a procedure from Grönqvist et al. (2017), we have, however, imputed skill measures for women using the draft scores of their brothers (if they have any). This enables us to estimate raw associations (across families) between the skill measures and fertility also for women, but the imputation cannot give us within twin-pair variation in the skills for women. We find that cognitive ability is firmly negatively related to fertility for women. The raw relationship between non-cognitive ability and fertility is instead slightly positive. Both ability types correlate positively to AFB. The estimates can be found in Table C2 in Kramarz et al. (2019).

Results for cognitive and non-cognitive skills for men are reported in Table 6. Starting with the raw associations, we find significant negative associations for cognitive skills for both number of children at age 45 (column 1) and the probability of having a child before age 45 (column 3 ). The raw associations for non-cognitive skills are, however, positive and very large; the results imply 0.17 more children and the males are 7 percentage points more likely to have a child for each standard deviation in non-cognitive skills. When introducing family fixed effects, the results across the two skill types are substantially harmonized. For cognitive ability, the estimate goes from being significantly negative to significantly positive. For non-cognitive ability, the twin fixed effects are instead reducing the association. This suggests that non-cognitive skills have a different correlation structure to family-level unobservables than cognitive skills, grades, and years of schooling. Turning to AFB, the results suggest that cognitive skills delay child birth more than non-cognitive skills. By introducing twin fixed effects, we substantially reduce the delaying effect of cognitive skills, and also (but to a much lesser extent) of non-cognitive skills.

\subsection{Potential concerns}

\subsubsection{Measurement errors}

A concern in most sibling fixed-effects applications is that measurement errors may be attenuating within-family estimates more than raw associations. In this setting, however, we note that the twins often are scored during the same day by the same individuals (same teachers for grades, same psychologist for non-cognitive scores). Thus, it is likely that the scores only deviate between twins when there are real differences, and potential measurement errors may be at least as distorting across families as within. Consistent with this view, we note that results are consistently more positive, but not consistently closer to zero, within twin pairs. The estimate of the association between cognitive ability and number of children at age 45 for men is significant and negative without twin fixed effects, but significant and positive when estimated within twin pairs. This cannot be explained by classical measurement errors. Similarly, the estimate of the association between years of schooling and number of children at age 45 for men 
Table 6 Fertility explained by military draft skills for men

\begin{tabular}{lllllll}
\hline & No. of children & No. of children & Children>0 & Children>0 & AFB & AFB \\
& $(1)$ & $(2)$ & $(3)$ & $(4)$ & $(5)$ & $(6)$ \\
\hline Cognitive skill & $-0.0212 * * *$ & $0.0935^{* *}$ & $-0.0072 * * *$ & $0.0240 *$ & $1.0491 * * *$ & -0.0185 \\
(std) & $(0.0013)$ & $(0.0272)$ & $(0.0005)$ & $(0.0096)$ & $(0.0068)$ & $(0.1662)$ \\
Non-cognitive skill & $0.1662 * * *$ & $0.1275^{* * *}$ & $0.0686^{* * *}$ & $0.0585^{* * *}$ & $0.1731^{* * *}$ & 0.0486 \\
(std) & $(0.0013)$ & $(0.0252)$ & $(0.0004)$ & $(0.0085)$ & $(0.0069)$ & $(0.1418)$ \\
Observations & $1,076,204$ & 10,784 & $1,076,204$ & 10,784 & 840,106 & 6,718 \\
Mean of dep & 1.7340 & 1.6942 & 0.7732 & 0.7517 & 29.3557 & 29.4408 \\
Twin FE & No & Yes & No & Yes & No & Yes \\
Equation & $(1)$ & $(2)$ & $(1)$ & $(2)$ & $(1)$ & $(2)$ \\
\hline
\end{tabular}

$A F B$, age at first birth. The outcomes in columns (1-4) are measured at age 45 . The skill measures are standardized (std) with mean 0 and standard deviation 1 for each draft year. In columns (1), (3), and (5), we include year of birth dummies. We implicitly control for year of birth also in columns (2), (4), and (6) since twins obviously have the same year of birth. In parentheses, we present standard errors clustered on the family level

${ }^{\dagger} p<.10 ; * p<.05 ; * * p<.01 ; * * * p<.001$

moves from a small positive estimate to a larger positive estimate when introducing twin fixed effects. The one result where we can be less sure, partly because we have fewer alternative metrics, is the estimate for non-cognitive abilities, an estimate which moved closer to zero when twin fixed effects were introduced.

\subsubsection{External validity of the twin samples}

A potential concern is that relations between variables in a sample of twins might not hold for the general population. We address this concern in two ways. First, we estimate the raw associations in the twin sample and compare it to the overall sample in Table 7 using the set-up with cognitive and non-cognitive abilities. To make this even more precise, we isolate the between-family effects in the twin sample directly using only across family variation in the twin sample for all of our models. Estimates from these models are very similar to the overall raw associations found for the general population (see Tables C3, C4 and C5 in Kramarz et al. 2019). ${ }^{18}$ Second, we reestimate all our family fixed-effects models using close siblings instead of twins. ${ }^{19}$ Since twin births generally are associated with more complications than single births, one could worry that differences in ability and fertility within twin pairs are more likely to reflect underlying health differences. This concern is not valid when studying close

\footnotetext{
18 The one exception is the relation between compulsory school grades and completed fertility for women (panel A of Table C4 in Kramarz et al. 2019). Here, the between-family estimates in the twin sample are more positive than the overall raw associations. Thus, the difference between columns 1 and 2 (and columns 3 and 4) in panel A of Table 5 should be interpreted with some caution. We note, however, that the within-family estimates in the twin sample in Table 5 still are larger than the between-family estimates in the twin sample in Table C4 in Kramarz et al. 2019. We also note that when we reproduce Table 5 using close siblings instead of twins (thus relying on a much larger sample), we still find that the inclusion of family fixed effects pushes the associations between grades and fertility in a positive direction (see Table A2 in the appendix).

${ }^{19}$ We include sibling pairs where the siblings are born within 3 years from each other.
} 
siblings. In Tables 9, 10, and 11 in the appendix, we replicate the results in Tables 4, 5, and 6 using samples of close siblings instead of twins. Throughout, the sibling estimates are very similar to the twin estimates. Taken together, these results corroborate the notion that it is the family fixed effects rather than the twins per se that are driving our results.

\subsubsection{Is it all about parental education?}

One concern is that the results may be driven by a simple observable factor such as parental education. We have therefore re-estimated the model for cognitive and noncognitive skills with and without controls for parental education in order to investigate the extent to which controlling for education changes the results in a similar way as the family fixed effect. The sample differs slightly from the overall sample since we only use subjects where we can measure parental education in these regressions; however, that does not matter for the results. The results shown in Table 7 show that controlling for parental education has a negligible effect both in the overall sample and in the twin sample. Thus, the profound impact of parental background we document in the paper does not appear to be driven by parental education.

\section{Explaining the role of families: family preferences and endogenous skills}

Our results imply that the association between fertility and skills/education is consistently more positive if estimated within twin pairs. This pattern holds for all measures, except for non-cognitive skills that (relative to cognitive skills) have a closer

Table 7 Fertility explained by military draft skills - role of parental education for men

\begin{tabular}{llllll}
\hline & $(1)$ & $(2)$ & $(3)$ & $(4)$ & $(5)$ \\
\hline Cognitive skill & $-0.0252^{* * *}$ & $-0.0119^{* * *}$ & -0.0288 & -0.0210 & $0.0664 * *$ \\
(std) & $(0.0016)$ & $(0.0016)$ & $(0.0176)$ & $(0.0183)$ & $(0.0320)$ \\
Non-cognitive skills & $0.1666^{* * *}$ & $0.1704 * * *$ & $0.1721^{* * *}$ & $0.1746 * * *$ & $0.1290^{* * *}$ \\
(std) & $(0.0015)$ & $(0.0015)$ & $(0.0175)$ & $(0.0175)$ & $(0.0309)$ \\
Specification & OLS & OLS & OLS & OLS & FE \\
Sample & All & All & Twins & Twins & Twins \\
Parental schooling & No & Yes & No & Yes & Yes (implicit) \\
Birth year FE & Yes & Yes & Yes & Yes & Yes (implicit) \\
Observations & 788,600 & 788,600 & 7714 & 7714 & 7714 \\
Mean of dependent variable & 1.7418 & 1.7418 & 1.6885 & 1.6885 & 1.6885 \\
\hline
\end{tabular}

The dependent variable is the number of children. The sample is restricted to individuals with information on parental education. This reduces the sample size by around $30 \%$. The outcome is measured at age 45 . The skill measures are standardized with mean 0 and standard deviation 1 for each draft year. In columns (1)-(4) we include year of birth dummies. We implicitly control for year of birth also in column (5) since twins obviously have the same year of birth. In parentheses, we present standard errors clustered on the family level

$\dagger p<.10 ; * p<.05 ; * * p<.01 ; * * * p<.001$ 
relationship to fertility than to education. These patterns suggest that shared family factors that are positively related to cognitive skills and education are negatively related to fertility, whereas the converse appears to be true for non-cognitive skills. In this section, we propose an explanation for these patterns.

To this end, we set up a stylized model of the process. To minimize detours, we assume that families derive utility from the fertility (in the spirit of Becker 1973) and education (as in, e.g., Chiappori et al. 2017) of their offspring. This should be considered as shorthand for the idea that one of the joys in life is to see one's children educate themselves and perhaps have successful careers, and another joy is the presence of (perhaps plentiful) grandchildren. The basic presumption is that families may differ in how much relative value they put on each of these two components.

We further assume that skills can be useful not only to foster education, but also to achieve success in the marriage market, and hence increase fertility, as in Becker (1973). We thus treat educational attainment and fertility as outcomes, whereas skills are considered individual endowments as in, e.g., Chiappori et al. (2017) and Chiappori et al. (2018).

We design our model with the aim of generating predictions that are consistent with our results based on a minimum of assumptions. ${ }^{20}$ Thus, the model is exceptionally stylized and simple. To align the model with the empirical analysis, we focus on the shared aspects of family background, i.e., we focus on parents' choice of the general direction in which to raise their children. This implies that we ignore the process wherein parents choose how to allocate resources within their set of children. The consequences of all such child-specific choices will show up in an individual residual together with the impact of sibling-specific luck, in the model just as in the empirical analysis. Despite the simple nature of the model, we end up with a precise empirical prediction which we take to the data.

We conjecture that our empirical patterns arise because families with a stronger preference for education invest more in cognitive skills for their children. In contrast, families with a stronger preference for fertility may invest more in non-cognitive skills. ${ }^{21}$ These endowments may be useful in both the educational "production function" and for fertility, but we let the different types of skills differ in their relative usefulness for the two outcomes as indicated by our data. Here, it should be noted that fertility, of course, is an outcome of a complicated process where the marriage market is one component, but other aspects may be relevant as well. We do not model those aspects in detail, but simply let the associations from the data result in a "production function" from skills and effort onto fertility. We return to extensions where effort towards fertility and education interact after having shown the basic model.

\subsection{The basic model}

Set-up Each individual is endowed with a set of skills arising from a combination of luck and choices made by his or her parents. These skills are useful for achieving a

\footnotetext{
${ }^{20}$ For an updated discussion of more elaborate models, see Chiappori et al. (2018).

${ }^{21}$ Results showing that our measures of cognitive and non-cognitive ability can be affected by schooling and resources in school (Carlsson et al. 2015; Fredriksson et al. 2013) support the assumption that they can be affected by parental investments.
} 
higher education and for fertility outcomes. There are two allocative choices in the model. Parents choose which skills to promote among their children. The child then chooses how to allocate effort between education and fertility.

Skills and outcomes Each individual $i$ is endowed with skills in two dimensions; $C$ (cognitive) and $N$ (non-cognitive). The outcomes of interest are denoted by $Y^{\tau}, \tau=E, F$, where $E$ denotes educational attainment and $F$ fertility. Outcomes are produced as linear, additively separable, functions of skill endowments:

$$
Y_{i}^{\tau}=\theta_{i}^{C \tau} C_{i}+\theta_{i}^{N \tau} N_{i}+\mu_{i}^{\tau}
$$

For simplicity, we assume that $\theta_{i}^{\mathrm{CE}}=\theta_{i}^{\mathrm{NF}}=1$ and $\theta_{i}^{\mathrm{NE}}=\theta_{i}^{\mathrm{CF}}=\theta<1$ such that cognitive ability is more productive for educational attainment and non-cognitive ability is more productive for fertility. ${ }^{22}$ The variable $\mu_{i}^{\tau}$ is the individual choice of effort on educational attainment and fertility respectively. To isolate the allocative nature of the choice, we impose the restriction $\mu_{i}^{F}+\mu_{i}^{E} \leq 1$.

Individuals are bestowed with skills and preferences by their families (indexed by j) Each family invests in skills of their children. Denote investments in skills by $\pi_{j}^{S}$ where the skill $(S)$ can be either cognitive $(C)$ or non-cognitive $(N) .{ }^{23}$ Skills also have a random component which varies across siblings within families. The random component is partly skill-specific $\left(u_{i}^{S}\right)$ and partly reflects that individuals may be better skilled in all dimensions, i.e., there is a joint individual fixed effect $\left(\alpha_{i}\right)$. Thus:

$$
\begin{gathered}
S_{\mathrm{ij}}=\pi_{j}^{S}+\alpha_{i}+u_{i}^{S}, \\
E\left(u_{i}^{S}\right)=0 .
\end{gathered}
$$

where we restrict the choices parenting styles to be one of how to allocate resources across two skill-dimensions by imposing $\pi_{i}^{N}+\pi_{i}^{C} \leq 1$.

We describe the individual skill component as a random draw, but it should be interpreted as a "reduced form" concept that also may contain elements of childspecific investments by parents if parental preferences differ across children or if they respond to individual-specific birth endowments. As our focus is on understanding differences across families, we focus on decisions related to the general direction of child rearing and not differences across children within families.

Families also automatically bestow their members with identical preferences over education (representing, e.g., consumption) and fertility (children). The family-specific utility function takes the form $e_{j} Y_{i}^{E}+\left(1-e_{j}\right) Y_{i}^{F}$ where the preference weight $\left(e_{j} \in(0\right.$,

\footnotetext{
22 This assumption is consistent with our empirical results (see Tables 3 and 6).

${ }^{23}$ As is evident from what we show below, families will not have incentives to vary skills across siblings.
} 
1)) is the inherited family-specific preference that represents the preference weight on education relative to fertility.

Optimization There are two choices to be made: Families choose how to invest in skills for their children and individuals choose how to allocate their effort between education and fertility (below we present an extension that allows for complementarity between the effort margins).

Individuals choose effort on the two markets $\left(\mu_{i}^{E}, \mu_{i}^{F}\right)$ so as to maximize their utility $U$ according to $U\left(Y_{i}^{E}, Y_{i}^{F}\right)=e_{j} Y_{i}^{E}+\left(1-e_{j}\right) Y_{i}^{F}$ subject to $\mu_{i}^{F}+\mu_{i}^{E} \leq 1$ and $\mu_{i}^{\tau} \geq 0$ and Eq. (3).

Similarly, parents choose investments over the two skills $\left(\pi_{j}^{N}, \pi_{j}^{C}\right)$ for their children so as to maximize their utility $V$ according to $V\left(Y_{i}^{E}, Y_{i}^{F}\right)=e_{j} Y_{i}^{E}+\left(1-e_{j}\right) Y_{i}^{F}$ subject to $\pi_{i}^{N}+\pi_{i}^{C} \leq 1$ and $\pi_{i}^{S} \geq 0$ and Eqs. (3) and (4).

Results Since both choices depend on the joint preference parameter and all aspects of production are additively separable and linear, the model derives an intuitive separation into two types of families: ${ }^{24}$

$$
\begin{aligned}
& e_{j}<\frac{1}{2} \leftrightarrow \mu_{i}^{F}=1 ; \quad \mu_{i}^{E}=0 ; \pi_{i}^{N}=1 ; \pi_{i}^{C}=0 \\
& e_{j}>\frac{1}{2} \leftrightarrow \mu_{i}^{F}=0 ; \quad \mu_{i}^{E}=1 ; \pi_{i}^{N}=0 ; \pi_{i}^{C}=1 .
\end{aligned}
$$

Thus, in families that prefer fertility over education $\left(e_{j}<\frac{1}{2}\right)$, investments will be geared towards non-cognitive skills and all effort will be geared towards fertility. For families that prefer education over fertility $\left(e_{j}>\frac{1}{2}\right)$, the converse is true for both choices. It is, however, straightforward to introduce reasons for the agents not to fully specialize in one of the two dimensions, and we present such an extension below. However, since predictions are intuitively visible in the simplified version presented in Eq. (5), and remain valid also in the extended version, we first derive the main conclusions here. Equation (5) implies that:

1) The within-family association between $\mathrm{C}$ and fertility is more positive than the overall association. The reason is that the overall association also captures the impact of the family preference which is reflected in high $C$ and a low fertility effort.

2) The within-family association between $\mathrm{N}$ and fertility is instead lower than the overall association. The reason is that the overall association also captures the impact of the family preference which is reflected in high $N$ and a high fertility effort.

3) The association between education and fertility is affected by the correlations of skills and effort since both are outcomes. There are two counteracting effects, one from the fact that generally better-skilled individuals are more likely to succeed on both markets (from $\alpha_{i}$ ), and one from the fact that individuals differ in skill sets and

\footnotetext{
${ }^{24} \mathrm{We}$ ignore the possibility that families are indifferent, i.e. $e_{j}=\frac{1}{2}$, without loss of intuition.
} 
how they choose to allocate (specialize) their effort. When estimating the model within twin pairs, we remove the effort and skill choices (since they are shared within the family), and isolate the effect of the skills $\left(\alpha_{i}\right)$. Thus, the within-family association should be more positive than the overall association.

\subsection{Extensions}

The basic model provides a stylized first-order approximation of the relationships under study. The simple linear additively separable functional forms generate corner solutions with only two types of families that make all predictions very clear. But if we, instead, let the return to effort be declining (by introducing $\ln \mu_{i}^{\tau}$ instead of $\mu_{i}^{\tau}$ in Eq. 3) such that

$$
Y_{i}^{\tau}=\theta_{i}^{C \tau} C_{i}+\theta_{i}^{N \tau} N_{i}+\ln \mu_{i}^{\tau}
$$

And similarly, let the returns to skill investments be declining by introducing $\ln \pi_{i}^{\tau}$ instead of $\pi_{i}^{\tau}$ in Eq. (4) such that

$$
\begin{gathered}
S_{\mathrm{ij}}=\ln \pi_{j}^{S}+\alpha_{i}+u_{i}^{S}, \\
E\left(u_{i}^{S}\right)=0 .
\end{gathered}
$$

We get solutions where both effort and investments are directly proportional to $e$. The first-order conditions are

$$
\begin{aligned}
\pi^{C} & =\frac{\theta^{\mathrm{NE}}+e\left(1-\theta^{\mathrm{NE}}\right)}{1+\theta^{\mathrm{NE}}}, \pi^{N}=\frac{1-e\left(1-\theta^{\mathrm{NE}}\right)}{1+\theta^{\mathrm{NE}}} . \\
\mu_{i}^{E} & =e_{i}, \mu_{i}^{F}=1-e_{i} .
\end{aligned}
$$

Thus, families with high $e$ invest more in $C$ and less in $N$. And, the same families put more effort into education, and less effort into fertility. Thus, the qualitative results remain unchanged.

The basic setup is also simplified in assuming that effort spent on education has no impact on fertility. But it is not implausible that, e.g., males benefit from their effort on the education front also for fertility. We can easily extend the model to allow for such complementarities. Assume that (6) holds for education (i.e., $Y_{i}^{E}=\theta_{i}^{\mathrm{CE}} C_{i}+\theta_{i}^{\mathrm{NE}} N_{i}+\ln \mu_{i}^{E}$ ) but that there are positive spillover effects from education onto fertility. We assume that the spillover effects have a lower effect on fertility than effort spent directly on fertility (otherwise everyone will trivially spend all effort on education). By defining a parameter $\rho<1$ and assuming:

$$
Y_{i}^{F}=\theta^{C F} C+\theta^{N F} N+\ln \mu^{F}+\rho \ln \mu^{E}
$$


we get the following first-order conditions for effort:

$$
\begin{gathered}
\mu^{E}=\frac{e+\rho(1-e)}{1+\rho(1-e)} \Rightarrow \frac{\partial \mu^{E}}{\partial e}>0, \frac{\partial \mu^{E}}{\partial \rho}>0 \\
\mu^{F}=\frac{1-e}{1+\rho(1-e)} \Rightarrow \frac{\partial \mu^{F}}{\partial e}<0, \frac{\partial \mu^{F}}{\partial \rho}<0
\end{gathered}
$$

This implies that the qualitative conclusions hold in the sense that a higher preference for education directs more effort into education and less effort towards fertility. However, an additional insight is that agents with more pronounced spillover effects (as defined by a higher $\rho$ ) invest more in education because this allows them to achieve both ends. It does not seem unlikely that this logic pertains more to men than to women and that the complementarity explains why the raw association between education and fertility is more positive for males.

A relevant concern is what happens if preferences are individual specific, rather than shared within families. This is fine as long as individual preferences, and thus endogenous effort, are not correlated with skills. But if individuals have preferences that are correlated with their skills (within twin-pairs), we will capture that as part of the skills in our regressions. Our conclusions regarding the role of family background would still be valid, but the withinfamily estimates would be biased. However, this is not unique to the twin identification strategy. In fact, we cannot think of any identification strategy that, with certainty, would circumvent this problem since any educational intervention that raises the skills of an individual simultaneously may affect the preferences, and hence the allocation of effort as well.

Finally, it can be noted that identical predictions as derived from our model could be generated by assuming that families differ in exogenous (e.g., genetic) skill endowments if these endowments are correlated with joint family preferences. Thus, our empirical results can be justified that if children that are born into families with a genetic predisposition for generating high cognitive abilities also have higher natural preferences for schooling rather than family formation, and the converse for noncognitive abilities. Note, however, that these predispositions need to vary at the family, not the individual, level which implies that the basic correlation structure remains intact relative to our model, but the intergenerational transmissions no longer have an endogenous component.

\subsection{An empirical test}

The model presupposes that agents in families where the preference for fertility is relatively strong will invest more in fertility and ensure that their children accumulate more non-cognitive skills relative to cognitive skills. To test this assumption, we investigate if parents with larger (residual) fertility-outcomes also raise children with a comparative advantage in non-cognitive skills. We first note that residuals from regressions explaining education and fertility by cognitive/non-cognitive skills (i.e., $Y_{i}^{\tau}=\theta_{i}^{C \tau} C_{i}+\theta_{i}^{N \tau} N_{i}+\mu_{i}^{\tau}$ ) provide a crude, but theory-consistent, measure of the effort devoted on each of the two markets. 
Thus, difference between the residuals $\left(\mu_{i}^{\text {Fertility }}-\mu_{i}^{\text {Education }}\right)$ is a proxy for the individual's relative preference weight on fertility $\left(e_{j}\right)$. According to our model, this preference weight should be related to the investment in non-cognitive relative to cognitive skills of the next generation within the same family, i.e., to $N_{\mathrm{ij}}-C_{\mathrm{ij}}=\pi_{j}^{N}-\pi_{j}^{C}+\Delta u_{i}$. Thus, interpreted from the male side (for data availability reasons), we expect fathers whose "fertility residual" is greater than his "education residual" to have a stronger preference for fertility, and therefore to raise sons with higher non-cognitive skills than cognitive skills.

In Table 8 , we test this association using data on all father-son pairs where we have information on both types of skills for fathers and sons. ${ }^{25}$ In the first two columns, we show the regressions that take out the residuals $\left(\mu_{i}^{F}, \mu_{i}^{E}\right)$ from the two $Y_{i}^{\tau}=\theta_{i}^{C \tau} C_{i}+\theta_{i}^{N \tau} N_{i}+\mu_{i}^{\tau}$ regressions. In column (3), we relate the difference in fathers residuals $\left(\mu_{i}^{F}-\mu_{i}^{E}\right)$ to the difference in skills of the sons $\left(N_{\mathrm{ij}}-C_{\mathrm{ij}}\right)$. The results show that fathers with a relatively high fertility residual are more likely to raise children with comparative skill advantages in the noncognitive dimension, as presumed by the model.

A potential concern is that the results are affected by a quantity-quality tradeoff that lets parents invest less in overall skills if they have more children. This could potentially crowd out skills in some dimension more than another, but our results are robust to accounting for the overall level of skills of the child as shown in column (4). We have also re-estimated the models after normalizing fertility and education to each have a standard deviation of one. This ensures that the scales of the two residuals are directly comparable. Reassuringly, our results remain robust (see Table C9 in Kramarz et al. 2019).

\section{Conclusions}

In this paper, we have analyzed how within twin-pair associations between fertility and skills/schooling differ from overall raw associations between the same variables. Our results imply that raw associations to a large degree reflect systematic differences across families. These differences are consistently pushing the raw associations in a negative direction: Within-family associations between fertility and skills/schooling are therefore considerably more positive than overall associations (the one exception is non-cognitive ability). For men, the effects of skills/schooling on completed fertility are firmly and consistently on the positive side once family background characteristics are accounted for. For women, the association between years of schooling and completed fertility is very close to zero, and the corresponding estimates with respect to grades

\footnotetext{
${ }^{25}$ To produce the results in columns 1 and 2 of Table 8 , we construct a sample containing all men born between 1950 and 1972 who have non-missing information on skills, years of schooling, and fertility. We do not require that these men have children. From the regressions in columns 1 and 2, we generate residuals for years of schooling and fertility. We then calculate the difference in residuals (fertility-education). To produce the results in columns 3 and 4 of Table 7, we start out from a sample of men with a known father. We then require these men to have non-missing information on skills and non-missing information on their father's difference in residuals (which comes from the exercise in columns 1 and 2). With these restrictions imposed, we end up with a sample of sons born between 1966 and 1987. A father can be matched to several sons in this sample, so we do not restrict the analysis to first-born sons.
} 
Table 8 Parental effort and investment

\begin{tabular}{|c|c|c|c|c|}
\hline & $\begin{array}{l}\text { Fertility (F) } \\
\text { (1) }\end{array}$ & $\begin{array}{l}\text { Education (E) } \\
(2)\end{array}$ & $\begin{array}{l}\text { N-C difference } \\
\text { (3) }\end{array}$ & $\begin{array}{l}\mathrm{N}-\mathrm{C} \text { difference } \\
\text { (4) }\end{array}$ \\
\hline & \multicolumn{2}{|c|}{ Parent regressions (1st stage) } & \multicolumn{2}{|c|}{ Child regressions (2nd stage) } \\
\hline \multirow[t]{2}{*}{ Cognitive (C) } & $-0.0151 * * *$ & $1.0727 * * *$ & & \\
\hline & $(0.0014)$ & $(0.0023)$ & & \\
\hline \multirow[t]{2}{*}{ Non-cognitive $(\mathrm{N})$} & $0.1674 * * *$ & $0.3167 * * *$ & & \\
\hline & $(0.0013)$ & $(0.0022)$ & & \\
\hline Residual correlation $(\mathrm{F}, \mathrm{E})$ & -0.0214 & & & \\
\hline \multirow[t]{2}{*}{ Parent residual difference (F-E) } & & & $0.0200^{* * *}$ & $0.0208 * * *$ \\
\hline & & & $(0.0013)$ & $(0.0013)$ \\
\hline \multirow[t]{2}{*}{ Child overall skills $(N+C)$} & & & & $0.0095 * * *$ \\
\hline & & & & $(0.0015)$ \\
\hline Observations & $1,027,581$ & $1,027,581$ & 167,956 & 167,956 \\
\hline
\end{tabular}

Fertility, number of children at 45. Education, years of schooling at 35 . In columns (1) and (2), we include year of birth dummies. In parentheses, we present standard errors clustered on the family level

$\dagger p<.10 ; * p<.05 ; * * p<.01 ; * * * p<.001$

from compulsory school appear to be positive. This pattern appears both for the probability of having children at all, and for the number of children. A main conclusion from the paper is thus that family background is the main explanation for the raw negative associations found for females, and the small benefits found for males in the raw data.

The results imply that family-specific factors with a positive relationship to fertility are negatively correlated with education, grades, and the cognitive skill levels of the family, but positively correlated with non-cognitive abilities. A possible reason for this pattern is endogenous accumulation of skills together with an intergenerational transmission of preferences for education and fertility. We present a stylized model that incorporates these features by postulating that families differ in the extent to which they value the fertility and the education of their offspring. Families who put a high relative value on fertility will have incentives to raise their children to have comparative-skill advantages in the non-cognitive rather than the cognitive dimension if non-cognitive skills are more important on the marriage and fertility markets as our results indicate. Our main empirical results, i.e., that cognitive human capital and fertility are negatively associated across families whereas the reverse is true for noncognitive abilities, arise if children also inherent the preferences of the parents. Consistent with our hypothesis, we find that children of fathers with higherthan-expected fertility have comparative advantages in the non-cognitive skill domain.

Overall, our paper strongly suggests that an important avenue for future research is to document how the intergenerational transmission of specific family attributes such as values, preferences, wealth, and abilities contributes to shaping the joint distribution of career and marriage market outcomes in different institutional settings. 


\section{Appendix}

Table 9 Fertility explained by years of schooling (siblings)

\begin{tabular}{lllllll}
\hline & No. of children & No. of children & Children $>0$ & Children $>0$ & AFB & AFB \\
& $(1)$ & $(2)$ & $(3)$ & $(4)$ & $(5)$ & $(6)$ \\
\hline Panel A. Women & & & & & & \\
Years of schooling & $-0.0412 * * *$ & $-0.0138^{* * *}$ & $-0.0049 * *$ & $0.0008^{*}$ & $0.6629 * * *$ & $0.3317 * * *$ \\
& $(0.0003)$ & $(0.0014)$ & $(0.0001)$ & $(0.0004)$ & $(0.0014)$ & $(0.0064)$ \\
Observations & $2,180,083$ & 350,536 & $2,180,083$ & 350,536 & $1,898,864$ & 274,690 \\
Mean of dep & 2.0061 & 2.0413 & 0.8706 & 0.8792 & 25.4741 & 25.3493 \\
Sibling FE & No & Yes & No & Yes & No & Yes \\
Equation & $(1)$ & $(2)$ & $(1)$ & $(2)$ & $(1)$ & $(2)$ \\
Panel B. Men & & & & & & \\
Years of schooling & $0.0055^{* * *}$ & $0.0291^{* * *}$ & $0.0061 * * *$ & $0.0112 * * *$ & $0.4524 * * *$ & $0.2203 * * *$ \\
& $(0.0003)$ & $(0.0014)$ & $(0.0001)$ & $(0.0004)$ & $(0.0015)$ & $(0.0072)$ \\
Observations & $2,233,137$ & 377,500 & $2,233,137$ & 377,500 & $1,801,464$ & 254,140 \\
Mean of dep & 1.8312 & 1.8430 & 0.7994 & 0.8036 & 28.4467 & 28.2077 \\
Sibling FE & No & Yes & No & Yes & No & Yes \\
Equation & $(1)$ & $(2)$ & $(1)$ & $(2)$ & $(1)$ & $(2)$ \\
\hline
\end{tabular}

Relates to Table 4 in the main paper. In columns (1), (3), and (5), we reproduce the estimates from the same columns in Table 4. AFB age at first birth. The outcomes in columns (1-4) are measured at age 45. In columns (1), (3), and (5), we include year of birth dummies. We implicitly control for year of birth also in columns (2), (4), and (6) since close siblings are born within three years from each other. In parentheses, we present standard errors clustered on the family level. $\dagger p<.10 ; * p<.05 ; * * p<.01$; *** $p<.001$ 
Table 10 Fertility explained by compulsory school grades (siblings)

\begin{tabular}{|c|c|c|c|c|c|c|}
\hline & $\begin{array}{l}\text { No. of children } \\
\text { (1) }\end{array}$ & $\begin{array}{l}\text { No. of children } \\
\text { (2) }\end{array}$ & $\begin{array}{l}\text { Children }>0 \\
\text { (3) }\end{array}$ & $\begin{array}{l}\text { Children }>0 \\
\text { (4) }\end{array}$ & $\begin{array}{l}\text { AFB } \\
(5)\end{array}$ & $\begin{array}{l}\text { AFB } \\
(6)\end{array}$ \\
\hline \multicolumn{7}{|c|}{ Panel A. Women } \\
\hline Grade (std) & $\begin{array}{l}-0.0579 * * * \\
(0.0028)\end{array}$ & $\begin{array}{l}-0.0233 \\
(0.0174)\end{array}$ & $\begin{array}{l}-0.0058^{* * * *} \\
(0.0008)\end{array}$ & $\begin{array}{l}-0.0001 \\
(0.0056)\end{array}$ & $\begin{array}{l}2.0571 * * * \\
(0.0125)\end{array}$ & $\begin{array}{l}1.0501 * * * \\
(0.0885)\end{array}$ \\
\hline Observations & 201,634 & 18,214 & 201,634 & 18,214 & 171,479 & 13,554 \\
\hline Mean of dep & 1.8760 & 1.9059 & 0.8500 & 0.8541 & 28.0331 & 28.0857 \\
\hline Sibling FE & No & Yes & No & Yes & No & Yes \\
\hline Equation & (1) & (2) & (1) & (2) & (1) & (2) \\
\hline \multicolumn{7}{|l|}{ Panel B. Men } \\
\hline Grade (std) & $\begin{array}{l}0.0356^{* * * *} \\
(0.0027)\end{array}$ & $\begin{array}{l}0.0808 * * * \\
(0.0176)\end{array}$ & $\begin{array}{l}0.0132 * * * \\
(0.0009)\end{array}$ & $\begin{array}{l}0.0217 * * \\
(0.0063)\end{array}$ & $\begin{array}{l}1.3831 * * * \\
(0.0134)\end{array}$ & $\begin{array}{l}0.5172 * * * \\
(0.1014)\end{array}$ \\
\hline Observations & 207,679 & 19,216 & 207,679 & 19,216 & 160,250 & 12,078 \\
\hline Mean of dep & 1.6507 & 1.7026 & 0.7684 & 0.7778 & 30.5544 & 30.5176 \\
\hline Sibling FE & No & Yes & No & Yes & No & Yes \\
\hline Equation & (1) & (2) & (1) & (2) & (1) & (2) \\
\hline
\end{tabular}

Relates to Table 5 in the main paper. In columns (1), (3), and (5), we reproduce the estimates from the same columns in Table 5. AFB, age at first birth. The outcomes in columns (1-4) are measured at age 45 . The grades are standardized with mean 0 and standard deviation 1 for each examination year. In columns (1), (3), and (5), we include year of birth dummies. We implicitly control for year of birth also in columns (2), (4), and (6) since close siblings are born within 3 years from each other. In parentheses, we present standard errors clustered on the family level

${ }^{\dagger} p<.10 ; * p<.05 ; * * p<.01 ; * * * p<.001$

Table 11 Fertility explained by military draft skills for men (siblings)

\begin{tabular}{|c|c|c|c|c|c|c|}
\hline & $\begin{array}{l}\text { No. of children } \\
\text { (1) }\end{array}$ & $\begin{array}{l}\text { No. of children } \\
\text { (2) }\end{array}$ & $\begin{array}{l}\text { Children }>0 \\
\text { (3) }\end{array}$ & $\begin{array}{l}\text { Children }>0 \\
\text { (4) }\end{array}$ & $\begin{array}{l}\text { AFB } \\
\text { (5) }\end{array}$ & $\begin{array}{l}\text { AFB } \\
\text { (6) }\end{array}$ \\
\hline Cognitive skill & $-0.0212^{* * * *}$ & $0.0537 * * *$ & $-0.0072 * * *$ & $0.0174 * * *$ & $1.0491 * * *$ & $0.3104 * * *$ \\
\hline (std) & $(0.0013)$ & $(0.0056)$ & $(0.0005)$ & $(0.0019)$ & $(0.0068)$ & $(0.0310)$ \\
\hline $\begin{array}{l}\text { Non-cognitive } \\
\text { skill }\end{array}$ & $0.1662 * * *$ & $0.1439 * * *$ & $0.0686^{* * *}$ & $0.0560 * * *$ & 0.1731 *** & $-0.1186^{* * * *}$ \\
\hline (std) & $(0.0013)$ & $(0.0050)$ & $(0.0004)$ & $(0.0017)$ & $(0.0069)$ & $(0.0281)$ \\
\hline Observations & $1,076,204$ & 190,910 & $1,076,204$ & 190,910 & 840,106 & 122,312 \\
\hline Mean of dep & 1.7340 & 1.7750 & 0.7732 & 0.7823 & 29.3557 & 29.2542 \\
\hline Sibling FE & No & Yes & No & Yes & No & Yes \\
\hline Equation & (1) & (2) & (1) & (2) & (1) & (2) \\
\hline
\end{tabular}

Relates to Table 6 in the main paper. In columns (1), (3), and (5), we reproduce the estimates from the same columns in Table 6. AFB, age at first birth. The outcomes in columns (1-4) are measured at age 45 . The skill measures are standardized (std) with mean 0 and standard deviation 1 for each draft year. In columns (1), (3), and (5), we include year of birth dummies. We implicitly control for year of birth also in columns (2), (4), and (6) since close siblings are born within 3 years from each other. In parentheses, we present standard errors clustered on the family level

${ }^{\dagger} p<.10 ; * p<.05 ; * * p<.01 ; * * * p<.001$ 
Acknowledgements We are grateful to Lena Hensvik, Helena Holmlund, Björn Öckert, Anna Sandberg, seminar participants at IFAU, as well as the editor, Shuaizhang Feng, and two anonymous referees for constructive comments and suggestions.

Funding Open access funding provided by Uppsala University. The article is in compliance with the ethical standards of the journal.

The study was not funded by any funding agency.

\section{Declarations}

Competing interests The authors declare no competing interests.

Open Access This article is licensed under a Creative Commons Attribution 4.0 International License, which permits use, sharing, adaptation, distribution and reproduction in any medium or format, as long as you give appropriate credit to the original author(s) and the source, provide a link to the Creative Commons licence, and indicate if changes were made. The images or other third party material in this article are included in the article's Creative Commons licence, unless indicated otherwise in a credit line to the material. If material is not included in the article's Creative Commons licence and your intended use is not permitted by statutory regulation or exceeds the permitted use, you will need to obtain permission directly from the copyright holder. To view a copy of this licence, visit http://creativecommons.org/licenses/by/4.0/.

\section{References}

Almlund M, Duckworth A, Heckman J, Kautz T (2011) Personality psychology and economics. In: Hanushek EA, Machin S, Woessmann L (ed) Handbook of the Economics of Education, volume 4. North Holland, Amsterdam, pp 1-181

Amin V, Behrman JR (2014) Do more-schooled women have fewer children and delay childbearing? Evidence from a sample of US twins. J Popul Econ 27:1-31

Andersson G, Rønsen M, Knudsen LB, Lappegård T, Neyer G, Skrede K, Teschner K, Vikat A (2009) Cohort fertility patterns in the Nordic countries. Demogr Res 20:313-352

Becker G (1973) A theory of marriage: Part I. J Polit Econ 81:813-846

Besemer S, Ahmad SI, Hinshaw SP, Farrington DP (2017) A systematic review and meta-analysis of the intergenerational transmission of criminal behavior. Aggress Violent Behav 37:161-178

Black SE, Devereux PJ, Salvanes KG (2008) Staying in the classroom and out of the maternity ward? The effect of compulsory schooling laws on teenage births. Econ J 118:1025-1054

Carlsson M, Dahl GB, Öckert B, Rooth DO (2015) The effect of schooling on cognitive skills. Rev Econ Stat 97:533-547

Carlstedt B (2000) Cognitive abilities - aspects of structure, process and measurement. Dissertation, University of Gothenburg

Caucutt EM, Lochner L (2020) Early and late human capital investments, borrowing constraints, and the family. J Polit Econ 128:1065-1147

Chen HY, Chen YH, Liao YK, Chen HP (2013) Relationship of fertility with intelligence and education in Taiwan: a brief report. J Biosoc Sci 45:567-571

Chiappori PA, Salanié B, Weiss Y (2017) Partner choice, investment in children, and the marital college premium. Am Econ Rev 107:2109-2167

Chiappori PA, Costa Dias M, Meghir C (2018) The marriage market, labor supply and education choice. J Polit Econ 126(S1):S26-S72

Copen CE, Silverstein M (2008) The transmission of religious beliefs across generations: do grandparents matter? J Comp Fam Stud 39:59-71

Cygan-Rehm K, Maeder M (2013) The effect of education on fertility: evidence from a compulsory schooling reform. Labour Econ 25:35-48 
Dobbie W, Grönqvist H, Niknami S, Palme M, Priks M (2018) The intergenerational effects of parental incarceration. NBER Working Paper No. w24186

Fleury N, Gilles F (2018) The intergenerational transmission of education. A meta-regression analysis. Educ Econ 26:557-573

Fort M, Schneeweis N, Winter-Ebmer R (2016) Is education always reducing fertility? Evidence from compulsory schooling reforms. Econ J 126:1823-1855

Fredriksson P, Öckert B, Oosterbeek H (2013) Long-term effects of class size. Q J Econ 128:249-285

Fredriksson P, Hensvik L, Skans ON (2018) Mismatch of talent: evidence on match quality, entry wages, and job mobility. Am Econ Rev 108:3303-3338

Frejka T, Calot G (2001) Cohort reproductive patterns in low-fertility countries. Popul Dev Rev 27:103-132

Grönqvist H, Hall C (2013) Education policy and early fertility: lessons from an expansion of upper secondary schooling. Econ Educ Rev 37:13-33

Grönqvist E, Öckert B, Vlachos J (2017) The intergenerational transmission of cognitive and non-cognitive abilities. J Hum Resour 52:887-918

Havari E, Savegnago M (2020) The intergenerational effects of birth order on education. J Popul Econ. https:// doi.org/10.1007/s00148-020-00810-5

Haworth CMA, Dale P, Plomin R (2008) A twin study into the genetic and environmental influences on academic performance in science in nine-year-old boys and girls. Int J Sci Educ 30:1003-1025

Heckman J, Stixrud J, Urzua S (2006) The effects of cognitive and noncognitive abilities on labor market outcomes and social behavior. J Labor Econ 24:411-482

Heineck G, Anger S (2010) The returns to cognitive abilities and personality traits in Germany. Labour Econ 17:535-546

Hensvik L, Skans ON (2016) Social networks, employee selection, and labor market outcomes. J Labor Econ 34:825-867

Jalovaara M, Neyer G, Andersson G, Dahlberg J, Dommermuth L, Fallesen P, Lappegård T (2019) Education, gender, and cohort fertility in the Nordic countries. Eur J Popul 35:563-586

Kanazawa S (2014) Intelligence and childlessness. Soc Sci Res 48:157-170

Kohler HP, Behrman JR, Schnittker J (2011) Social science methods for twins data: integrating causality, endowments, and heritability. Biodemogr Soc Biol 57:88-141

Kolk M, Barclay K (2019) Cognitive ability and fertility among Swedish men born 1951-1967: evidence from military conscription registers. Proc R Soc B 286(1902)

Kramarz F, Skans ON, Rosenqvist O (2019) Skills, education and fertility and the confounding impact of family background. IFAU Working Paper 2019:10

Kravdal Ø, Rindfuss RR (2008) Changing relationships between education and fertility: a study of women and men born 1940 to 1964. Am Sociol Rev 73:854-873

Lilieblad B, Ståhlberg B (1977) Reliability of the psychological assessments at conscription. Report from the Swedish Armed Forces Research Department

Lindqvist E, Vestman R (2011) The labor market returns to cognitive and noncognitive ability: evidence from the Swedish enlistment. Am Econ J Appl Econ 3:101-128

Martin SP (2000) Diverging fertility among US women who delay childbearing past age 30. Demography 37 : 523-533

McCrary J, Royer H (2011) The effect of female education on fertility and infant health: evidence from school entry policies using exact date of birth. Am Econ Rev 101:158-195

Meisenberg G (2008) How universal is the negative correlation between education and fertility? J Soc Polit Econ Stud 33:205-227

Meisenberg G (2010) The reproduction of intelligence. Intelligence 38:220-230

Monstad K, Propper C, Salvanes KG (2008) Education and fertility: evidence from a natural experiment. Scand J Econ 110:827-852

Mood C, Jonsson JO, Bihagen E (2012) Socioeconomic persistence across generations: cognitive and noncognitive processes. In: Ermisch J, Jäntti M, Smeeding TM (eds) From parents to children: the intergenerational transmission of advantage. Russell Sage, New York, pp 53-84

Nandi A, Nicoletti C (2014) Explaining personality pay gaps in the UK. Appl Econ 46:3131-3150

Nisén J, Martikainen P, Kaprio J, Silventoinen K (2013) Educational differences in completed fertility: a behavioral genetic study of Finnish male and female twins. Demography 50:1399-1420

Nisén J, Myrskylä M, Silventoinen K, Martikainen P (2014) Effect of family background on the educational gradient in lifetime fertility of Finnish women born 1940-50. Popul Stud 68:321-337 
Nisén J, Martikainen P, Myrskylä M, Silventoinen K (2018) Education, other socioeconomic characteristics across the life course, and fertility among Finnish men. Eur J Popul 34:337-366

Nybom M (2017) The distribution of lifetime earnings returns to college. J Labor Econ 35:903-952

Rodgers JL, Kohler HP, McGue M, Behrman JR, Petersen I, Bingley P, Christensen K (2008) Education and cognitive ability as direct, mediating, or spurious influences on female age at first birth: behavior genetic models fit to Danish twin data. Am J Sociol 114(S1):S202-S232

Rosenzweig MR, Zhang J (2009) Do population control policies induce more human capital investment? Twins, birth weight and China's “one-child policy". Rev Econ Stud 76:1149-1174

Silles MA (2011) The effect of schooling on teenage childbearing: evidence using changes in compulsory education laws. J Popul Econ 24:761-777

Tropf FC, Mandemakers JJ (2017) Is the association between education and fertility postponement causal? The role of family background factors. Demography 54:71-91

Wang M, Fuerst J, Ren J (2016) Evidence of dysgenic fertility in China. Intelligence 57:15-24

Woodley MA, Meisenberg G (2013) A Jensen effect on dysgenic fertility: an analysis involving the National Longitudinal Survey of Youth. Personal Individ Differ 55:279-282

Yi CC, Chang CF, Chang YH (2004) The intergenerational transmission of family values: a comparison between teenagers and parents in Taiwan. J Comp Fam Stud 35:523-545

Publisher's note Springer Nature remains neutral with regard to jurisdictional claims in published maps and institutional affiliations. 